\title{
PENGARUH PENAMBAHAN 2,5\% Ti-B TERHADAP SIFAT MEKANIK POROS BERULIR (SCREW) BERBAHAN DASAR 40\% ALUMINIUM BEKAS DAN 60\% PISTON BEKAS
}

\author{
Putri Rachmawati ${ }^{1}$, Andika Wisnujati ${ }^{2}$ \\ ${ }^{1} \& 2$ Program Vokasi Teknik Mesin Universitas Muhammadiyah Yogyakarta \\ ${ }^{1)}$ Email: putri.rachmawati@ vokasi.umy.ac.id \\ Jl. Ringroad Barat, Tamantirto, Kasihan, Tamantirto, Kasihan, Bantul, D.I.Yogyakarta
}

\begin{abstract}
Soybean miller machine is an innovative machine that makes it easy for tempeh producers. This machine uses a threaded shaft (screw), making it easier for tempeh producers in producing more higienic tempeh easy and fast threaded shaft (screw) is made of aluminium alloy metal.

This research study is intended it find the ideal alloy as material for the manufacture of threaded shaft (screw). This research study used a mixture of $40 \%$ aluminium profil and $60 \%$ of used pistons with $2.5 \%$ Ti-B (Titanium-Baron) as a smooth refiner. The mold used is a metal mold (die casting) with a mold temperature heating of $200^{\circ} \mathrm{C}$.

The test to know the mechanical properties of the aluminium alloy is tensile and hardness test. Based on the test results of the tes tis that the specimen with heating temperature of $200^{\circ} \mathrm{C}$ producers a maximum tensile stress of $148.08 \mathrm{MPa}$, while for vickers hardness testing yields an average hardness of $95.1 \mathrm{Kg} / \mathrm{mm}^{2}$. The results of the experiments using heating temperature of $200^{\circ} \mathrm{C}$ and $400^{\circ} \mathrm{C}$ obtained microstructure on aluminium alloy casting specimens with $2.5 \%$ Ti-B addition, the most evently formed phase ini all specimens was Aluminium (Al) phase.
\end{abstract}

Keywords: Aluminium alloy, Threaded shaft (Screw), mechanic properties

\section{PENDAHULUAN}

Mesin pengupas kedelai adalah sebuah alat atau mesin yang memiliki fungsi untuk mengupas kulit ari kedelai sekaligus memecah kedelai menjadi dua. Mesin ini menggunakan poros berulir (Screw) sehingga dengan inovasi mesin pengupas kedelai akan memudahkan para produsen tempe, karena cara kerja proses yang sederhana dan mampu menghemat biaya produksi.

Poros berulir (Screw) ini terbuat dari logam paduan aluminium. Alumunium merupakan salah satu bahan non ferro yang sangat banyak dimanfaatkan dalam kehidupan sehari-hari, baik pada kalangan industri besar dan kecil maupun pada kalangan rumah tangga. Aluminium mempunyai sifat yang sangat menguntungkan yaitu: ringan $(1 / 3$ berat baja, tembaga, kuningan), tahan korosi sehingga dapat digunakan di hampir segala lingkungan seperti di lingkungan atmosfer, air (termasuk air garam), minyak dan banyak zat kimia lainnya. Alumunium memiliki tingkat konduktivitas listrik dan panas yang tinggi dan tahan terhadap serangan korosi di berbagai lingkungan, termasuk pada temperature ruang, memiliki struktur FCC (Face Centerd Cubic), tetapi memiliki keuletan di kondisi temperature rendah serta memiliki temperatur lebur $660^{\circ} \mathrm{C}$. Alumunium adalah suatu logam yang secara termodinamika adalah logam yang reaktif.

Komponen otomotif, umumnya menggunakan proses pengecoran dengan cetakan pasir kerena mempunyai keuntungan yaitu biaya produksinya murah, namun kelemahan dari metode pengecoran ini kualitas produk yang dihasilkan masih banyak ditemukan cacat pengecoran seperti penyusutan (shringkage), retak panas dan sifat mekanis yang rendah sehingga mengurangi kualitas produk (Brown, 1999).

Komposisi paduan dan pemilihan proses pada saat pengecoran dapat mempengaruhi struktur mikro dari aluminium paduan. Struktur mikro dapat 
dirubah dengan penambahan unsur tertentu dari paduan Al-(Al-Si) yang dapat memperbaiki sifat mampu cor (castability), sifat mekanis dan mampu mesin yang baik (machinability). Ukuran butir dari aluminium paduan tergantung pada jumlah inti yang terbentuk dalam logam cair sebelum dimulainya solidifikasi. Titanium pada umumnya ditambahkan ke dalam logam cair sebesar 0,02 sampai $0,15 \%$. Ti$\mathrm{B}$ ini berfungsi sebagai penghalus butir (grain refiner). Ti-B sangat penting sekali dalam memperbaiki sifat dari aluminium paduan seperti sifat mekanis, mengurangi porositas, lebih tahan terhadap retak panas (hot cracking), merubah struktur dan memperbaiki hasil akhir pada permukaannya.

Penelitian ini menggunakan paduan alumunium profil $(\mathrm{Al})$ dengan komposisi berat $40 \%$ dan piston bekas (Al-Si) $60 \%$, dengan menggunakan proses cetakan logam (die casting) dengan suhu cetakan $200^{\circ} \mathrm{C}$ dan $400^{\circ} \mathrm{C}$ dengan penambahan unsur Ti-B (Titanium - Baron) pada paduan 2,5\% sebagai penghalus butir. Penggunaan kedua bahan tersebut diharapkan dapat diketahui sifat mekanis dengan melakukan pengujian tarik dan kekerasan. Penelitian ini bertujuan untuk mengetahui pengaruh proses pengecoran pada paduan aluminium dengan penambahan unsur Ti-B sebesar 2,5\% menggunakan cetakan logam (die casting).

\section{LANDASAN TEORI}

Penelitian tentang paduan Al-Si telah banyak dilakukan oleh peneliti sebelumnya. Sulung Andi F, (2005) meneliti paduan $75 \% \mathrm{Al}-25 \% \mathrm{Si}$ dengan menggunakan dapur lebur atau krusibel. Pengecoran aluminium paduan dengan variasi tekanan angin $0,3,4$ dan 5 Psi menggunakan kompresor dan didapatkan hasil yang lebih baik pada tekanan 5 Psi yaitu $13,66 \mathrm{Kg} / \mathrm{mm}^{2}$ sedangkan tanpa tekanan didapatkan hasil $10,15 \mathrm{Kg} / \mathrm{mm}^{2}$. Selanjutnya dengan adanya tekanan pada saat proses pengecoran akan meningkatkan nilai kekerasan sebesar BHN $163 \mathrm{Kg} / \mathrm{mm}^{2}$ dan juga mencegah adanya porositas atau cacat pada hasil coran, hal tersebut terjadi karena pemberian tekanan pada saat proses pengecoran mengakibatkan cairan logam mendapat tekanan yang merata sehingga coran yang terbentuk akan lebih padat dan udara yang ada di dalam cetakan dipaksa keluar sehingga menminimalkan adanya porositas.

Gazanion, dkk (2002) menyarankan bahwa agar tidak terlalu lama menahan logam cair dalam dapur, karena akan terjadi penggumpalan dan pengendapan dari penghalus butir Ti-B sebelum dituang kecetakan. Penambahan penghalus butir Ti-B pada paduan Al-Si mempengaruhi bentuk pori, karena Ti-B mempengaruhi proses solidifikasi sehingga merubah bentuk morfologi dendrite, yakni dari bentuk columnar ke bentuk equiaxed. Dimana pori tumbuh pada batas butir dan menghasilkan pori berbentuk bulat. Ti-B sebagai penghalus butir tidak terlalu signifikan mempengaruhi sifat fluiditas logam cair.

Tabel 1. Komposisi Paduan Aluminium

\begin{tabular}{|c|l|}
\hline No. Seri & \multicolumn{1}{|c|}{ Komposisi Paduan } \\
\hline 1xxx & Aluminium Murni \\
\hline $2 \times x x$ & $\begin{array}{l}\text { Paduan Aluminium - } \\
\text { Tembaga }\end{array}$ \\
\hline $3 \times x x$ & $\begin{array}{l}\text { Paduan Aluminium - } \\
\text { Mangan }\end{array}$ \\
\hline $4 \times x x$ & Paduan Aluminium-Silicon \\
\hline $5 \times x x$ & $\begin{array}{l}\text { Paduan Aluminium- } \\
\text { Magnesium }\end{array}$ \\
\hline $6 \times x x$ & $\begin{array}{l}\text { Paduan Aluminium- } \\
\text { Magnesium-Silicon }\end{array}$ \\
\hline $7 \times x x$ & Paduan Aluminium-Seng \\
\hline $8 \times x x$ & $\begin{array}{l}\text { Paduan Aluminium-Timah- } \\
\text { Litium }\end{array}$ \\
\hline $9 x x x$ & $\begin{array}{l}\text { Disiapkan Dipenggunaan } \\
\text { Dimasa Depan }\end{array}$ \\
\hline
\end{tabular}

Hafiz, (2016) menganalisa penambahan unsur Ti-B (Titanium-Baron) sebanyak $0,02 \%$ pada paduan aluminium $50 \% \mathrm{Al}-50 \%(\mathrm{Al}-\mathrm{Si})$ menggunakan cetakan pasir (sand casting) pada 2 jenis 
variasi pemanasan suhu cetakan yaitu $200^{\circ} \mathrm{C}$ dan $300^{\circ} \mathrm{C}$. Pengujian yang dilakukan untuk mengetahui sifat-sifat mekanis dan fisis paduan aluminium tersebut yaitu pengujian tarik (Tensile Strength), kekerasan (Hardeness), dan metalografi dengan mikroskop optik. Hasil pengujian maksimum terjadi pada bahan paduan $\mathrm{Al}-\mathrm{Si}$ dengan penambahan Ti-B $0,02 \%$ dan dengan pemanasan suhu cetakan $200^{\circ} \mathrm{C}$ menghasilkan tegangan tarik maksimum sebesar $618,8 \mathrm{~N} / \mathrm{mm}^{2}$, sedangkan untuk pengujian kekerasan (Vickers Hardness Number) menghasilkan angka kekerasan sebesar $103 \mathrm{Kg} / \mathrm{mm}^{2}$, dan untuk hasil metalografi diperoleh data struktur yang terbentuk adalah fase hypereutectic silikon yang membentuk fasa silikon primer. Fasa tersebut memberikan ketahanan aus yang tinggi.

$$
\text { Supriyadi A dkk, (2011) }
$$

menganalisa pengaruh variasi penambahan Ti-B pada bahan ADC 12 menggunakan proses pengecoran High Pressure Die Casting (HPDC) terhadap peningkatan kualitas bahan hasil coran sebagai bahan sepatu rem sepeda motor.Tahapan yang peneliti lakukan adalah pembuatan cetakan logam, merakit cetakan logam pada mesin HPDC, penyiapan material, peleburan,variasi penambahan Grain refiner Ti-B, 0,04\%, 0,08\%, 0,12\%, 0,16\%, $0,2 \%, 0,24 \%$, penuangan pada temperatur cetakan $200 \mathrm{oC}$, temperatur tuang $7000 \mathrm{C}$ dan tekan injeksi $7 \mathrm{MPa}$, pemeriksaan coran, analisa kekuatan coran dengan uji tarik dan kekerasan. Dari hasil pengamatan dan analisa pengujian didapatkan bahwa pada penambahan Ti-B $0,08 \%$ dihasilkan kekuatan tarik sebesar $300 \mathrm{~N} / \mathrm{mm} 2$ dan kekerasan 78,5 HRB hasil ini merupakan sifat mekanik yang paling baik dibandingkan apabila tidak mendapatkan penambahan inokulan Ti-B.

Aluminium adalah logam yang memiliki kekuatan yang relatif rendah dan lunak. Aluminium merupakan logam yang ringan dan memiliki ketahanan korosi yang baik, hantaran listrik yang baik dan sifatsifat lainnya. Umumnya aluminium dicampur dengan logam lainnya sehingga membentuk aluminium paduan. Material ini dimanfaatkan bukan saja untuk peralatan rumah tangga, tetapi juga dipakai untuk keperluan industri, kontsruksi, dan lain sebagainya. (Surdia,1992).

Titanium adalah sebuah unsur kimia dalam tabel periodik yang memiliki simbol $\mathrm{Ti}$ dan nomor atom 22. Unsur ini merupakan logam transisi yang ringan, kuat, berkilau, tahan korosi (termasuk tahan terhadap air laut, aqua regia, dan klorin) dengan warna putih-metalikkeperakan. Ti-B ini berfungsi sebagai penghalus butir (grain refiner). TiB sangat penting sekali dalam memperbaiki sifat dari aluminium paduan seperti sifat mekanis, mengurangi porositas, lebih tahan terhadap retak panas (hot cracking), merubah struktur dan memperbaiki hasil akhir pada permukaannya (Brown, 1999). Umumnya pada paduan Al-Si ditambahkan penghalus butir Ti-B sebagai inokulan, ada beberapa jenis penghalus butir baru yang diperkenalkan seperti Ti-B ataupun Ti-C yang setiap penghalus butir tersebut mempunyai ciri dan manfaat yang spesifik (ASM Speciality Handbook Aluminiun, 1993).

Cetakan yang biasa digunakan pada pengecoran logam adalah cetakan logam. Cetakan logam umumnya sering digunakan karena porositas yang terjadi lebih sedikit bila dibandingkan dengan cetakan pasir. Pada penuangan, logam cair mengalir melalui pintu cetakan, maka bentuk pintu cetakan harus dibuat sedemikian rupa sehingga tidak mengganggu aliran logam cair. Pada umumnya logam cair dituangkan dengan pengaruh gaya berat, walaupun dapat juga dipergunakan tekanan pada logam cair selama atau setelah penuangan. Pengecoran cetak adalah suatu cara pengecoran dimana logam cair ditekan ke dalam cetakan logam dengan tekanan tinggi.

Untuk membuat coran, harus dilakukan beberapa proses seperti pencairan, pembuatan cetakan, penuangan, pembongkaran dan pembersihan coran. 
Untuk mencairkan logam bermacammacam dapur yang dipakai. Umumnya kupola (dapur induksi frekwensi rendah) dipergunakan untuk besi cor, dapur busur listrik (dapur induksi frekwensi tinggi) digunakan untuk baja tuang dan dapur krus untuk paduan tembaga atau coran paduan ringan, karena dapur ini dapat mengolah logam cair yang baik dan sangat ekonomis untuk logam-logam tersebut. Cetakan pasir jarang digunakan karena kemungkinan terjadinya porositas lebih besar. (Hafiz, 2016).

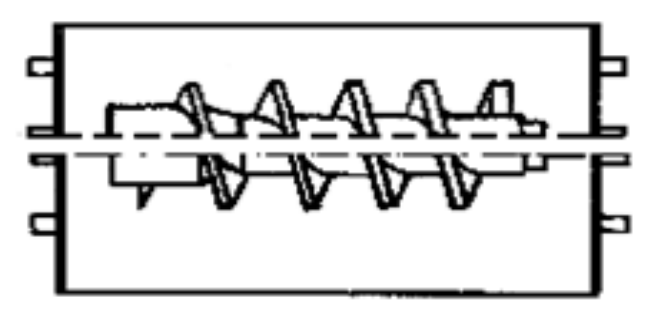

Gambar 1. Pola Cetakan

\section{A. Aluminium Alloy}

Alumunium merupakan salah satu logam non ferrous. Aluminium dalam bentuk paduan yang sering dikenal dengan istilah aluminium alloy merupakan jenis aluminium yang digunakan cukup besar saat ini. Dalam sektor perindustrian, alumunium dikembangkan dengan begitu pesat. Dan dapat diolah menjadi berbagai macam produk dengan lebih ekonomis. Alumunium merupakan logam ringan dengan berat jenis $2.643 \mathrm{~g} / \mathrm{cm} 3$ dan titik cairnya $660^{\circ} \mathrm{C}$.

Bauksit adalah salah satu sumber alumunium, dan banyak terdapat didaerah Bintan dan Kalimantan. Bauksit dapat diolah dengan proses bayer untuk mendapatkan alumina yang selanjutnya diolah kembali untuk mendapatkan alumunium. Untuk menghasilkan $500 \mathrm{Kg}$ alumunium diperlukan $550 \mathrm{Kg}$ bauksit, $450 \mathrm{~kg} \mathrm{NaOH}, 31.5$ ton $\mathrm{H} 2 \mathrm{O}$ dan 7.5 ton uap. Bauksit dapat juga diolah menggunakan proses elektrolisa. Untuk 1 $\mathrm{kg}$ alumunium diperlukan $4 \mathrm{~kg}$ bauksit, $0.6 \mathrm{~kg}$ karbon, dan criolit.

\section{B. Pengecoran Logam}

Pengecoran logam merupakan salah satu ilmu pengetahuan tertua yang dipelajari oleh umat manusia. Ilmu pengecoran logam terus berkembang dengan pesat. Berbagai macam metode pengecoran logam telah ditemukan dan terus disempurnakan, diantaranya adalah centrifugal casting, investment casting, dan sand casting serta masih banyak lagi metode-metode lainnya. Pengecoran adalah membuat komponen dengan cara menuangkan bahan yang dicairkan ke dalam cetakan. Bahan di sini dapat berupa metal maupun non-metal. Untuk mencairkan bahan diperlukan furnace (dapur kupola). Furnace adalah sebuah dapur atau tempat yang dilengkapi dengan heater (pemanas). Bahan padat dicairkan sampai suhu titik cair dan dapat ditambahkan campuran bahan seperti chrome, silikon, titanium, aluminium dan lain-lain agar bahan menjadi lebih baik.

Aplikasi dari proses pengecoran sangat banyak salah satunya dapat ditemukan dalam pembuatan komponen permesinan. Proses pengecoran dilakukan melalui beberapa tahap mulai dari pembuatan cetakan, persiapan dan peleburan logam, penuangan logam cair ke dalam cetakan, pembersihan coran dan proses daur ulang pasir cetakan. Hasil pengecoran disebut dengan coran atau benda cor. Proses pengecoran bisa dibedakan atas 2 yaitu proses pengecoran dan proses pencetakan. Proses pengecoran tidak menggunakan tekanan sewaktu mengisi rongga cetakan sedangkan proses pencetakan adalah logam cair ditekan agar mengisi rongga cetakan. Cetakan untuk kedua proses ini berbeda dimana proses pengecoran cetakan biasanya dibuat dari pasir sedangkan proses pencetakan, cetakannya dibuat dari logam. Proses pengecoran logam akan menghasilkan aluminium dengan sifat - sifat yang diinginkan. Aluminium murni memiliki sifat mampu cor dan sifat mekanis yang tidak baik, maka dipergunakanlah aluminium alloy untuk memperbaiki sifat 
tersebut. Beberapa elemen alloy yang sering ditambahkan diantaranya tembaga, magnesium, mangan, nikel, silikon dan sebagainya.

\section{Pengujian kekerasan}

Pengujian yang dilakukan pada penelitian ini antara lain:

\section{1) Pengujian kekerasan vickers.}

Yang dimaksud dengan kekerasan adalah daya tahan suatu bahan (permukaan bahan) terhadap penetrasi atau indentasi (penusukan atau pemasukan) bahan lain yang lebih keras, dengan bentuk tertentu dibawah pengaruh daya tertentu. Pengujian ini didasari pada kemampuan permukaan untuk menerima beban dari mesin uji kekerasan. Dengan diketahui kekerasan suatu benda maka dapat diketahui gambaran tentang kekuatan benda tersebut. Pengujian kekerasan dimaksudkan untuk mengetahui harga kekerasan benda uji pada beberapa bagian kemudian akan diketahui distribusi kekerasan dari benda uji tersebut, sehingga nanti bisa didapatkan hasil kekerasan terbaik melalui pengujian kekerasan vickers ini. Pengujian dilakukan dengan mesin uji keras (Vickers Hardness Testing Machine) dengan cara melakukan penekanan pada sampel menggunakan penekan berbentuk piramida intan yang dasarnya bujur sangkar. Besarnya sudut puncak identor piramida intan $136^{\circ}$.

Penyiapan benda uji pada pengujian ini adalah sama dengan penyiapan benda uji struktur mikro, dimana diperlukan permukaan yang halus untuk mempermudah dalam pengambilan titik uji. Pengujian kekerasan sistem vickers juga berdasarkan atas kedalaman penetrasi, namun dalam perhitungan yang digunakan adalah diameter bekas penetrasi. Penetrator yang digunakan berbentuk piramida bersudut puncak $136^{\circ}$ dengan pembebanan $30 \mathrm{~kg}$. Bekas injakan penetrator diamati dengan menggunakan mikroskop untuk diukur panjang diagonal rata-rata injakan penetrator.
Besarnya angka kekerasan dihitung berdasarkan persamaan:

VHN = Vickers Hardness Number

$\mathrm{P}=$ Beban yang digunakan $(\mathrm{kg})$

$\mathrm{D}=$ Panjang diagonal rata- rata $(\mathrm{mm})$

$\Theta=$ Sudut antara permukaan intan yang berhadapan $=136^{\circ}$

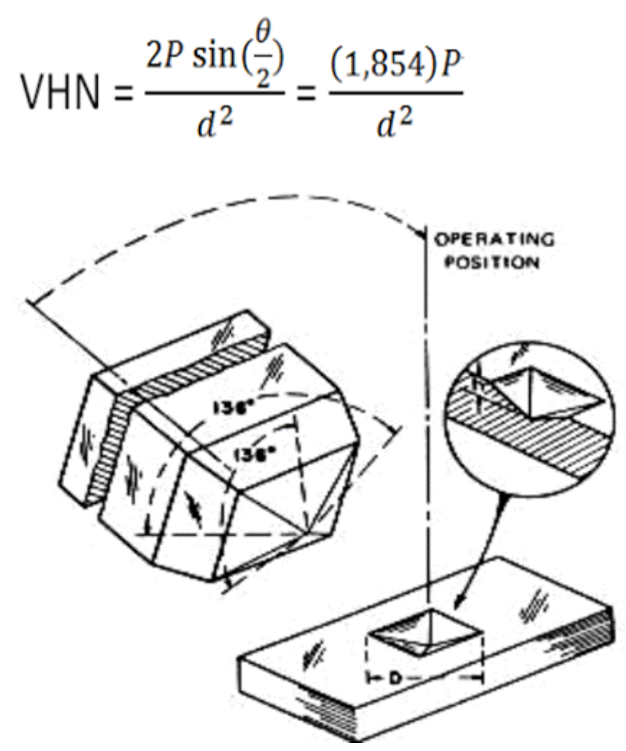

Gambar 2. Skematis Prinsip indentasi dengan metode kekerasan vickers

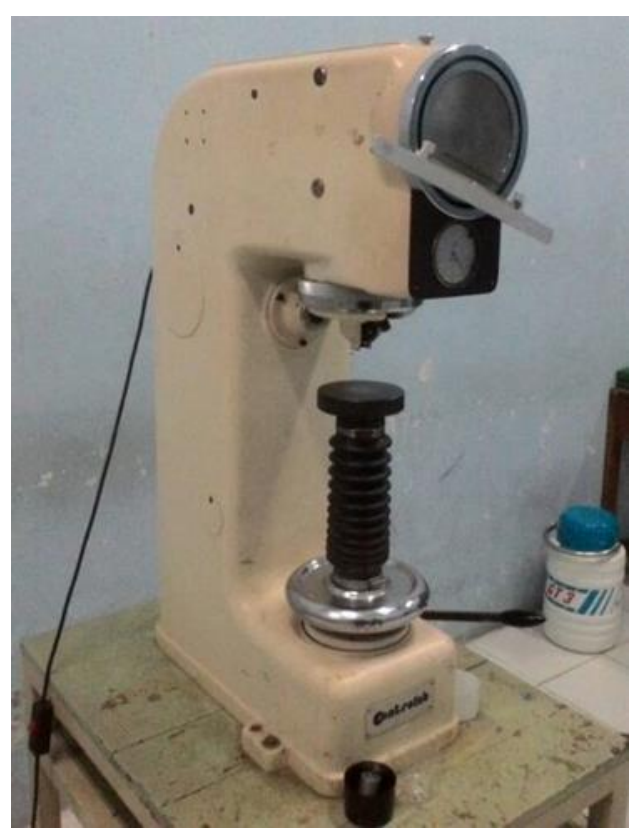

Gambar 3. Alat uji kekerasan vickers (Vickers Hardness Tester)

Langkah pengujian kekerasan vickers adalah: 
1. Benda uji disiapkan untuk dilakukan uji kekerasan.

2. Benda uji diletakkan pada landasan yang sesuai.

3. Meletakkan penetrator pada benda uji.

4. Memberikan pembebanan sebesar $30 \mathrm{Kg}$.

5. Menunggu saat pembebanan selama kira-kira 15 menit.

6. Mengangkat pembebanan dari permukaan bahan.

7. Melihat hasil uji kekerasan yang ditampilkan pada layar monitor.

8. Mengulangi pengujian seperti langkah-langkah diatas sebanyak 9 kali pada tempat yang berbedabeda.

9. Panjang diagonal diukur dengan skala pada mikroskop pengujur jejak.

Hasil identifikasi uji vickers yang berbentuk persegi empat dapat dilihat melalui perbesaran pada mikroskop: Pembesaran 50: 1 milimeter 18 strip Pembesaran 100: 1 milimeter 36 strip Pembesaran 200: 1 milimeter 72 strip

\section{2) Pengujian struktur mikro}

Pengamatan perubahan struktur mikro akibat pengaruh variasi suhu cetakan diamati dengan pengujian metalografi yang dilakukan pada spesimen uji. Pengujian struktur mikro ini bertujuan untuk mengamati struktur mikro pada paduan Al$\mathrm{Si}+\mathrm{Ti}-\mathrm{B}$, terutama untuk mengamati perubahan struktur mikro dari material yang diakibatkan dari proses peleburan dengan menggunakan variasi suhu cetakan. Penyiapan spesimen untuk pengujian struktur mikro sama dengan persiapan untuk pengujian kekerasan vickers. Penyiapan spesimen dilakukan dengan cara memotong spesimen, kemudian dibingkai dengan resin dan selanjutnya dilakukan pengamplasan kemudian pemolesan serta pemberian larutan kimia (etsa). Pengamplasan dilakukan dengan kertas amplas yang bertingkat kekasarannya sedangkan pemolesan dilakukan dengan autosol dan kain bludru. Sampel yang telah mengkilap dietsa dengan larutan kimia yaitu dengan menggunakan $\mathrm{NaOH}+\mathrm{H} 2 \mathrm{O}$ $50 \%$, untuk tahap selanjutnya diamati struktur mikronya dengan menggunakan mikroskop optik.

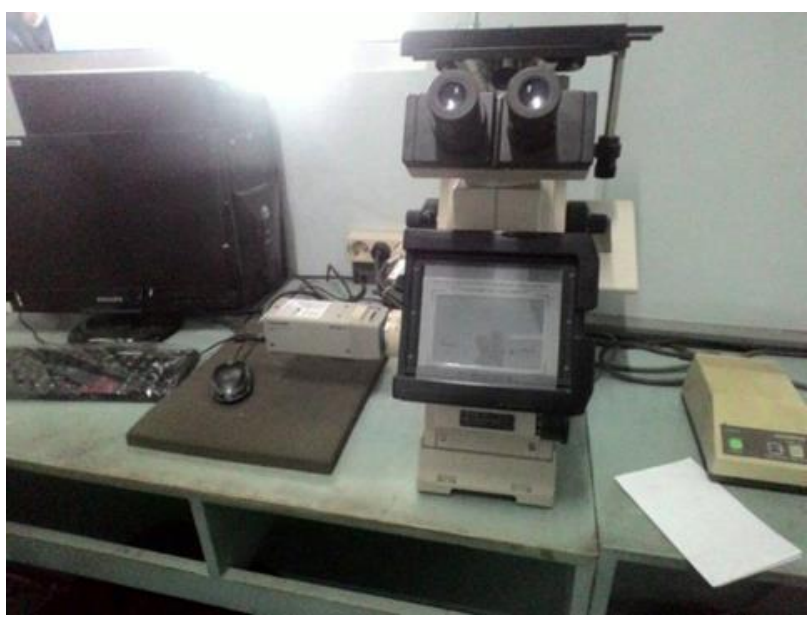

Gambar 4. Mikroskop optik (Metallurgical Microscope Invertgo Tipe)

\section{3) Pengujian tarik}

Pengujian tarik dilakukan untuk mengetahui nilai kekuatan tarik dari spesimen. Sifat mekanik yang dipelajari adalah kekuatan tarik. Pengujian tarik dilakukan untuk mengetahui tegangan tarik, tegangan luluh dan regangan pada bahan pembuatan poros berulir (screw). Urutan proses pengujian tarik yang dilakukan adalah sebagai berikut:

1. Menentukan panjang (Lo) dan diameter awal (do).

2. Kemudian benda uji diletakkan pada mesin uji tarik pada alat penjepit.

3. Akibat gaya/beban tarik yang diberikan pada benda uji, maka benda uji akan mengalami pertambahan panjang dan pada saat beban tertentu benda uji akan putus.

4. Mengamati dan mencatat besarnya beban yang diterima oleh benda uji dan dicatat sebagai beban maksimum.

5. Mengukur pertambahan panjang yang dialami benda uji setelah 
benda uji yang patah tersebut disambung kembali.

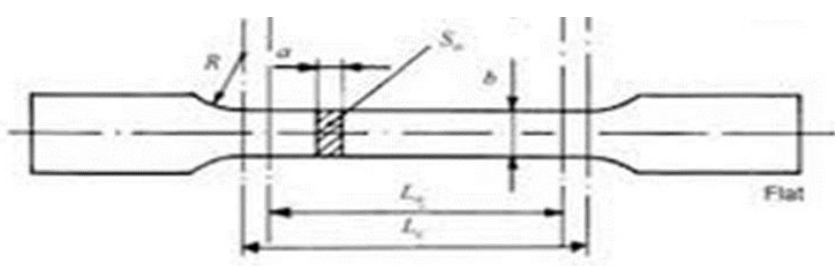

Gambar 5. Bentuk spesimen untuk pengujian tarik model pelat

Kekuatan tarik merupakan kemampuan bahan untuk menerima beban tarik. Pengujian dilakukan dengan menggunakan mesin uji tarik, dengan cara menjepit sampel dengan kuat dan beban diberikan secara kontinyu sampai sampel tersebut putus. Sifat-sifat mekanis yang diharapkan untuk diketahui adalah kekuatan (tegangan) tarik, kekuatan luluh dan regangan dengan perhitungan menggunakan rumus berikut:

бu: Tegangan tarik $\left(\mathrm{N} / \mathrm{mm}^{2}\right)$

$\mathrm{Pu}$ : Beban tarik $(\mathrm{kN})$

Ao: Luas penampang tarik mula-mula $\left(\mathrm{mm}^{2}\right)$

$$
\sigma u=\frac{P u}{A n}
$$

\section{$\varepsilon:$ Regangan $(\%)$}

Lo: Panjang awal spesimen ( $\mathrm{mm})$

L: Panjang akhir spesimen (mm)

$$
\varepsilon=\frac{L-L o}{L o} \times 100 \%
$$

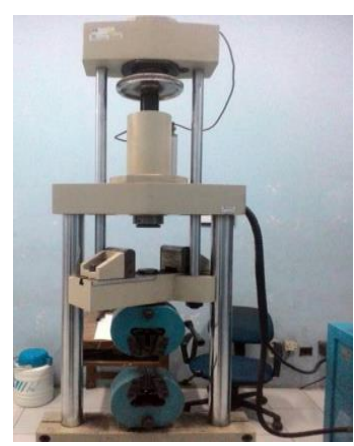

Gambar 6. Alat pengujian tarik (Universal Testing Material)

\section{METODE PENELITIAN}

\section{A. Alat Penelitian}

Beberapa alat yang digunakan antara lain:

1. Timbangan digital digunakan untuk uji density

2. Mesin uji tarik Servopulser Shimadzu, digunakan untuk menguji tarik dari suatu material.

3. Mesin uji kekerasan, menggunakan uji kekerasan mikro vickers untuk mengetahui kekerasan bahan.

\section{B. Bahan Penelitian}

Pelaksanaan penelitian ini digunakan adalah aluminium profil bekas dan aluminium paduan $\mathrm{Si}$ yang diambil dari piston bekas. Inokulan sebagai penghalus butir menggunakan penambahan unsur TiB.

\section{Tempat Penelitian}

Pelaksanaan pembuatan bahan (specimen) pengecoran dilakukan di IKM Pengecoran Logam dan UPT Logam, Nitikan, Yogyakarta. Pengujian bahan dilakukan di laboratorium bahan, Departemen Teknik Mesin dan Industri Fakultas Teknik, Universitas Gadjah Mada Yogyakarta.

D. Alur Penelitian

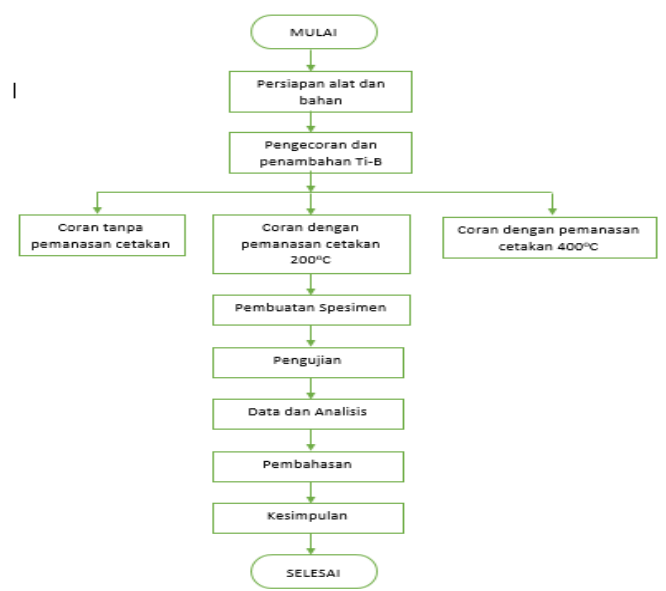


Gambar 7. Diagram Alir proses penelitian

\section{E. Metode}

Dalam penelitian ini dilakukan proses pengecoran aluminium profil dan aluminium dari piston bekas yang mengandung unsur silikon dengan penambahan unsur Ti-B sebagai penghalus butir. Pengujian yang dilakukan adalah sifat mekanik dengan suhu logam $200{ }^{\circ} \mathrm{C}$ dan $400^{\circ} \mathrm{C}$.

\section{F. Proses Pengecoran}

Langkah awal sebelum proses pengecoran adalah membuat pola atau cetakan dari logam (die cast). Penentuan kup, drag dan permukaan pisah harus mempertimbangkan beberapa hal sebagai berikut:

a) Pola harus mudah dikeluarkan dari cetakan

b) Penempatan inti harus mudah dan dibuat secara teliti

c) Sistem saluran harus dapat mengalirkan logam cair dengan mudah dan hasilnya optimum.

Bahan-bahan yang dipakai untuk pembuatan pola adalah logam besi cor. Dalam hal tertentu atau pemakaian khusus.

Proses peleburan dimulai dengan memasukkan bahan baku aluminium. Setelah aluminium mencair, kemudian dimasukkan potongan-potongan piston bekas dan Ti-B sebesar 2,5\% dari berat total bahan baku yang akan dilebur. Setelah seluruh bahan ini mencair secara homogen diperiksa komposisinya, bila komposisi dari logam cair telah sesuai dengan yang diharapkan dan temperaturnya telah mencapai temperatur yang diharapkan maka logam cair telah dapat dituang.

\section{G. Pengujian Tarik}

Sifat mekanik yang dipelajari adalah kekuatan tarik. Pengujian tarik dilakukan untuk mengetahui tegangan tarik, tegangan luluh dan regangan pada bahan pembuatan

Kekuatan tarik merupakan kemampuan bahan untuk menerima beban tarik. Pengujian dilakukan dengan menggunakan mesin uji tarik Servopulser Shimadzu dengan cara menjepit sampel dengan kuat dan beban diberikan secara kontinyu sampai sampel tersebut putus. Sifat-sifat mekanis yang diharapkan untuk diketahui adalah kekuatan (tegangan) tarik, kekuatan luluh dan regangan dengan perhitungan menggunakan rumus [1-2]:

$$
\sigma u=\frac{P u}{A o}
$$

$\sigma \mathrm{u}$ : Tegangan Tarik $\left(\mathrm{N} / \mathrm{mm}^{2}\right)$

$\mathrm{Pu}$ : Beban Tarik (KN)

Ao : Luas Penampang Tarik Mulamula $\left(\mathrm{mm}^{2}\right)$

$$
\varepsilon=\frac{L-L o}{L o} \times 100 \% \text {. }
$$

$\varepsilon \quad$ : Regangan $(\%)$

Lo : Panjang Awal Spesimen (mm)

L : Panjang Akhir Spesimen (mm)

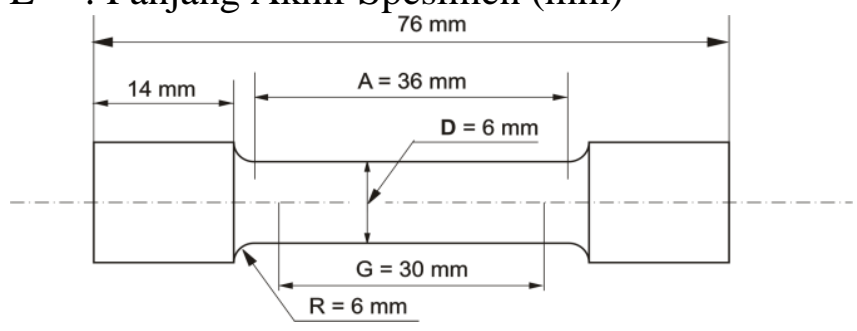

Gambar 8. Spesimen uji tarik

\section{H. Pengujian Kekerasan}

Pengujian kekerasan dimaksudkan untuk mendapatkan data perubahan kekerasan dari bahan akibat adanya pengelasan. Pengujian dilakukan dengan mesin uji keras (Vickers Hardness Testing Machine) dengan cara melakukan penekanan pada sampel menggunakan penekan berbentuk piramida intan yang dasarnya bujur sangkar. Besarnya angka kekerasan dihitung berdasarkan persamaan [3]:

$V H N=1,854 \times \frac{p}{d^{2}}$

VHN : Angka kekerasan Vickers

(Hardness Vickers Number)

$\mathrm{P}$ : Beban yang digunakan $(\mathrm{kg})$

$\mathrm{d}$ : Diagonal identasi $(\mathrm{mm})$

\section{HASIL DAN PEMBAHASAN}




\section{A. Hasil Penelitian}

Hasil Penelitian ini pada pembuatan spesimen dilakukan dengan proses pengecoran metode die casting atau menggunakan cetakan logam. Bahan yang digunakan adalah piston bekas dan aluminium profil. Proses pengecoran dilakukan dengan suhu cetakan yaitu: $200^{\circ} \mathrm{C}$ dan $400{ }^{\circ} \mathrm{C}$. Logam coran dalam proses pengecoran ini dilebur dalam tungku peleburan dengan bahan bakar gas. Tungku ini hanya mempunyai satu ruangan yaitu daerah kruss untuk tempat mencairkan logam. Logam cair dan logam yang akan dicairkan terdapat dalam ruangan yang sama. Bagian atas dari tungku ini terbuka lebar, sehingga memudahkan pengisian logam yang akan dilebur. Proses peleburan pada logam, pertama memasukkan bahan baku aluminium bekas, kemudian kedua potongan-potongan piston bekas, dan langkah ketiga apabila benar-benar cair dengan sempurna barulah dimasukkan TiB. Setelah seluruh bahan logam mencair secara homogen, maka logam cair telah dapat dituang kedalam cetakan seperti ditunjukan oleh Gambar 10.

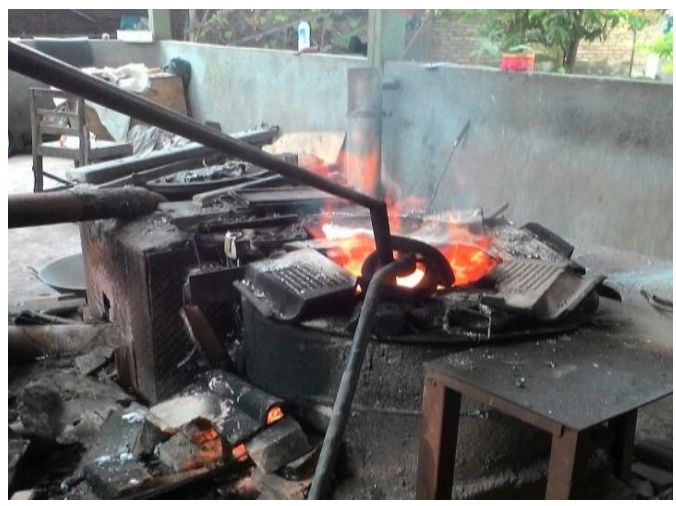

Gambar 10. Dapur Peleburan sederhana

\section{1) Data Spesimen}

Pada pembuatan spesimen ini, untuk komposisi bahan peleburan yang digunakan dalam penelitian ini adalah;

Tabel 2. Komposisi bahan baku peleburan

\begin{tabular}{ccc}
\hline Keterangan & $\begin{array}{c}\text { Komposisi } \\
\text { Pembuat Screw }\end{array}$ & Bahan \\
\hline
\end{tabular}

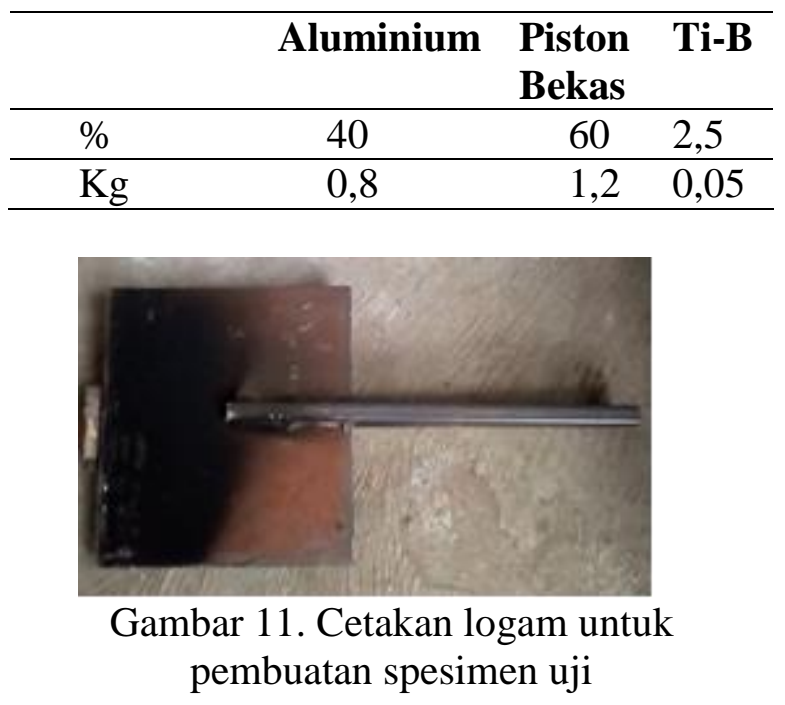

\section{2) Data Spesimen}

Kualitas suatu produk pengecoran itu dilihat dari proses saat penuangan logam cair sesuai dengan kondisi dan pencetakannya, semakin baik komposisi logam cair, semakin baik kualitas dari hasil cor nya.
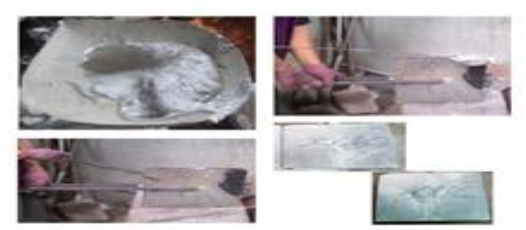

Gambar 12. Benda hasil coran

\section{3) Hasil Uji Tarik}

Pengujian tarik pada penelitian ini bertujuan untuk mengetahui kekuatan serta deformasi plastis yang terjadi pada spesimen paduan Al-(Al-Si) + Ti-B, dengan menggunakan suhu cetakan logam $200{ }^{\circ} \mathrm{C}$ dan $400^{\circ} \mathrm{C}$ untuk bahan pembuatan poros berulir (screw). Spesimen uji mengacu ASTM E8M, dengan alat uji Universal Testing Machine, dengan kapasitas alat maksimum $200 \mathrm{kN}$.

\begin{tabular}{|c|c|c|c|c|c|c|c|c|c|}
\hline No. & $\begin{array}{c}\text { Kode } \\
\text { spes. }\end{array}$ & $\begin{array}{c}\text { Lebar } \\
(\mathrm{mm})\end{array}$ & $\begin{array}{c}\text { Tebal } \\
(\mathrm{mm})\end{array}$ & $\begin{array}{c}(\mathrm{Lo}) \\
(\mathrm{mm})\end{array}$ & $\begin{array}{c}(\mathrm{Lf}) \\
(\mathrm{mm})\end{array}$ & $\begin{array}{c}(\Delta \mathrm{u}) \\
(\mathrm{mm})\end{array}$ & $\begin{array}{c}\text { P Max. } \\
(\mathrm{kN})\end{array}$ & $\begin{array}{c}\text { Reg. } \\
(\varepsilon) \\
(\%)\end{array}$ & $\begin{array}{c}\text { Teg. } \\
(\text { (gu) } \\
(\mathrm{MMa})\end{array}$ \\
\hline 1 & B.2-a & 12,51 & 4,03 & 49,81 & 50,05 & 0,24 & 8,06 & 0,48 & 159,87 \\
2 & B.2-b & 12,44 & 3,96 & 49,49 & 49,60 & 0,11 & 7,22 & 0,22 & 146,56 \\
3 & B.2-c & 12,33 & 3,99 & 49,46 & 49,77 & 0,31 & 6,78 & 0,63 & 137,81 \\
\hline 4 & B.3-a & 12,52 & 3,99 & 50,15 & 50,24 & 0,09 & 7,34 & 0,18 & 146,93 \\
5 & B.3-b & 12,64 & 3,97 & 49,51 & 49,91 & 0,40 & 4,33 & 0,81 & 86,29 \\
6 & B.3-c & 12.7 & 3,99 & 50,05 & 50,10 & 0,05 & 4,55 & 0,10 & 89,79 \\
\hline 7 & B.4-a & 12,45 & 3,87 & 50,06 & 50,51 & 0,45 & 5,31 & 0,90 & 110,21 \\
8 & B.4-b & 12,35 & 3,86 & 49,32 & 49,64 & 0,32 & 8,31 & 0,65 & 174,32 \\
9 & B.4-c & 12,59 & 3,84 & 49,71 & 49,87 & 0,16 & 6,79 & 0,32 & 140,45 \\
\hline
\end{tabular}


Tabel 3. Hasil Pengujian Tarik

\section{B. Pembahasan}

Hasil pengujian tarik diatas dapat dilihat bahwa nilai rata - rata kekuatan tarik pada pemanasan suhu cetakan $200^{\circ} \mathrm{C}$ adalah 148,08 $\mathrm{MPa}$, kemudian pada suhu pemanasan cetakan $400^{\circ} \mathrm{C}$ adalah 141,66 MPa. Data tersebut menunjukkan bahwa perlakuan pemanasan cetakan dengan suhu $200^{\circ} \mathrm{C}$ pada hasil pengecoran aluminium paduan dengan penambahan 2,5\% Ti-B menghasilkan lebih tinggi dibandingkan dengan variasi pemanasan cetakan dengan $200^{\circ} \mathrm{C}$ pada hasil pengecoran aluminium paduan dengan penambahan $2,5 \% \mathrm{Ti}-\mathrm{B}$ dengan suhu $400^{\circ} \mathrm{C}$.

Hasil pengujian kekerasan Vickers pada pembuatan poros berulir (Screw) menggunakan 9 titik, dengan alat uji vickers hardness dengan pembebanan 30 $\mathrm{Kg}$.

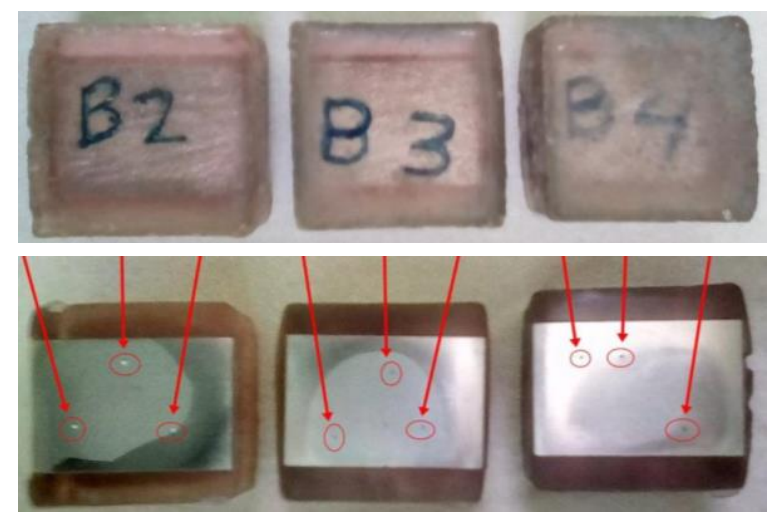

Gambar 13. Spesimen uji kekerasan vickers

Berdasarkan data hasil uji kekerasan vickers pada tiga spesimen hasil peleburan yang telah ditambah unsur Ti-B sebesar 2,5\% dapat dianalisis, yaitu:

1) Spesimen dengan variasi suhu cetakan $200^{\circ} \mathrm{C}$.

Dari hasil pengujian kekerasan vickers yang telah dilakukan diperoleh harga kekerasan tertinggi 97,6 $\mathrm{Kg} / \mathrm{mm}^{2}$, sementara kekerasan terendah 92,6 $\mathrm{Kg} / \mathrm{mm}^{2}$ dan kekerasan rata-rata diperoleh $95,1 \mathrm{Kg} / \mathrm{mm}^{2}$.

2) Spesimen dengan variasi suhu cetakan $400^{\circ} \mathrm{C}$
Dari hasil pengujian kekerasan vickers yang telah dilakukan diperoleh harga kekerasan tertinggi $88,0 \mathrm{Kg} / \mathrm{mm}^{2}$, sementara kekerasan terendah 82,7 $\mathrm{Kg} / \mathrm{mm}^{2}$ dan kekerasan rata-rata diperoleh $86,2 \mathrm{Kg} / \mathrm{mm}^{2}$.

\section{KESIMPULAN}

Hasil pengujian maksimum terjadi pada bahan paduan Al-Si dengan penambahan Ti-B 2,5\% pada pemanasan suhu cetakan $400^{\circ} \mathrm{C}$ menghasilkan tegangan tarik maksimum rata-rata sebesar 148,08 MPa. Sedangkan untuk pengujian kekerasan vickers menghasilkan angka kekerasan sebesar 97,6 Kg/mm².

VI.SARAN
Penelitian dengan menggunakan
paduan aluminium ini, dapat
dikembangkan untuk diaplikasikan pada
beberapa komponen-komponen mesin
yang lain selain pada poros berulir (screw).

\section{DAFTAR PUSTAKA}

ASM Handbook, 1992, Metallography and Microstructures, Volume 9, ASM International.

ASM Handbook,1992, Sifates and Selection: Nonferrous Alloys and Special Purpose Materials, Volume 2, ASM International

ASM Handbook, 1992, Casting, Volume 15, ASM Internasional

Djatmiko E,. dan Budiarto, Analisis Sifat Mekanis Dan Struktur Mikro Pada Produk Paduan Al-Si Metode Squeezing Casting, Prosiding Seminar Nasional Pengembangan Energi Nuklir IV, 2011.

Eva, Aziz Nur, 2012, Analisis Sifat Fisis Dan Mekanis Aluminium Paduan AL-SI-CU Dengan Menggunakan Cetakan Pasir, Laporan Tugas 
Akhir Fakultas Teknik UMS, Juli 2012, Surakarta.

Damayanthi, T.L, 2011, Uji Lama

Perebusan dan Lama Pengadukan Terhadap Kualitas Kedelai. Universitas Sumatera Utara.

Hasim, 2002, Mesin Penggiling Kedelai Untuk Pembuatan Tempe. Jurusan Teknik Mesin dan Industri, Fakultas Teknik, Universitas Gadjah Mada, Yogyakarta.

Hidayat, Taufik, 2010, Bantalan Gelinding. http://www.scribd.com (diakses pada 23/02/2011, 11:30am)

Hieronymus, B. S., 1993, SK Mentan No. 501/Kpts/TP.830/8/1984, tentang Teknologi Tepat Guna Pembuatan Tempe dan Tahu Kedelai. Penerbit Kanisius. Yogyakarta.

Ismanto, 2009, Pulley Type V. http://gambarteknik.blogspot.com/2 009/08/pulley-type-v.html (Diakses 09/09/2013, 09:45am).

Iswara, Padjar, 2010, Kedelai Setelah Satu Dekade. Majalah Tempo (19 Maret 2010).

Jonathan, 2009, Sepuluh Tahun Bersama Tempe. Pos Kupang.

Khurmi, R.S. J.K. Gupta. 2004. A Textbook of Machine Design. S.I. Units. Eurasia Publishing House (Pvt) Ltd. New Delhi.

Murata K., Ikehata H., 2006, Studies on the Nutritional Value of Tempeh, Journal of Food Science. 